NASA/CR—2004-213209

\title{
Evaluation of Pulsed Plasma Thruster Micropulsing
}

Lynn Arrington

QSS Group, Inc., Cleveland, Ohio 
Since its founding, NASA has been dedicated to the advancement of aeronautics and space science. The NASA Scientific and Technical Information (STI) Program Office plays a key part in helping NASA maintain this important role.

The NASA STI Program Office is operated by Langley Research Center, the Lead Center for NASA's scientific and technical information. The NASA STI Program Office provides access to the NASA STI Database, the largest collection of aeronautical and space science STI in the world. The Program Office is also NASA's institutional mechanism for disseminating the results of its research and development activities. These results are published by NASA in the NASA STI Report Series, which includes the following report types:

- $\quad$ TECHNICAL PUBLICATION. Reports of completed research or a major significant phase of research that present the results of NASA programs and include extensive data or theoretical analysis. Includes compilations of significant scientific and technical data and information deemed to be of continuing reference value. NASA's counterpart of peerreviewed formal professional papers but has less stringent limitations on manuscript length and extent of graphic presentations.

- TECHNICAL MEMORANDUM. Scientific and technical findings that are preliminary or of specialized interest, e.g., quick release reports, working papers, and bibliographies that contain minimal annotation. Does not contain extensive analysis.

- CONTRACTOR REPORT. Scientific and technical findings by NASA-sponsored contractors and grantees.
- CONFERENCE PUBLICATION. Collected papers from scientific and technical conferences, symposia, seminars, or other meetings sponsored or cosponsored by NASA.

- SPECIAL PUBLICATION. Scientific, technical, or historical information from NASA programs, projects, and missions, often concerned with subjects having substantial public interest.

- TECHNICAL TRANSLATION. Englishlanguage translations of foreign scientific and technical material pertinent to NASA's mission.

Specialized services that complement the STI Program Office's diverse offerings include creating custom thesauri, building customized databases, organizing and publishing research results ... even providing videos.

For more information about the NASA STI Program Office, see the following:

- Access the NASA STI Program Home Page at http://www.sti.nasa.gov

- E-mail your question via the Internet to help@sti.nasa.gov

- Fax your question to the NASA Access Help Desk at 301-621-0134

- Telephone the NASA Access Help Desk at 301-621-0390

- Write to:

NASA Access Help Desk

NASA Center for AeroSpace Information 7121 Standard Drive

Hanover, MD 21076 
NASA/CR-2004-213209

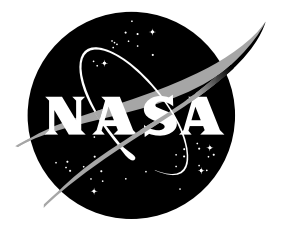

\section{Evaluation of Pulsed Plasma Thruster Micropulsing}

Lynn Arrington

QSS Group, Inc., Cleveland, Ohio

Prepared for the

40th Joint Propulsion Conference and Exhibit

cosponsored by the AIAA, ASME, SAE, and ASEE

Fort Lauderdale, Florida, July 11-14, 2004

Prepared under Contract NAS3-00145

National Aeronautics and

Space Administration

Glenn Research Center 
Available from

NASA Center for Aerospace Information 7121 Standard Drive

Hanover, MD 21076
National Technical Information Service 5285 Port Royal Road Springfield, VA 22100

Available electronically at http://gltrs.grc.nasa.gov 


\title{
Evaluation of Pulsed Plasma Thruster Micropulsing
}

\author{
Lynn Arrington \\ QSS Group, Inc. \\ Cleveland, Ohio 44135
}

This paper evaluates the concept of pulsed plasma thruster (PPT) micropulsing. Micropulsing was a premise behind a power processing unit (PPU) and an energy storage unit (ESU) design that for certain mission profiles, it was advantageous to operate a PPT at lower energy but higher frequency rather than at a higher energy but lower frequency. This premise allows for reductions in the ESU volume and mass without paying a penalty in thrust. To complete the evaluation, an independent spark plug initiation unit, a high voltage power supply and a variety of mica foil capacitors at 2.6, 5, 10, and $20 \mu \mathrm{F}$ were used to conduct a series of tests on a single PPT to map performance levels of thrust, impulse bit, efficiency and specific impulse over a comparable power range. Testing at NASA Glenn Research Center was conducted with breadboard PPT hardware. The test results showed that operating in the lower energy ESU micropulsing mode produced similar thrust levels to a higher energy ESU operating at high power level. Further testing however showed a reduction in specific impulse and efficiency when the smaller capacitances were used at the highest power levels. This would require more fuel mass for a mission that was predominately high power, potentially negating the ESU mass savings. Therefore, micropulsing is advantageous where most of a mission profile occurs at low power, but retains the ability to conduct high thrust maneuvers when necessary.

$\begin{array}{ll}\text { E } & \text { energy } \\ \mathrm{f} & \text { frequency } \\ \mathrm{I}_{\mathrm{bit}} & \text { impulse bit } \\ \mathrm{I}_{\mathrm{sp}} & \text { specific impulse } \\ \mathrm{P} & \text { power } \\ \mathrm{T} & \text { thrust } \\ \eta & \text { efficiency }\end{array}$

\section{Nomenclature}

\section{Introduction}

The National Aeronautics and Space Administration (NASA) Pulsed Plasma Thruster Program consists of flight demonstration experiments and base research and development efforts being conducted through a combination of in-house work, contracts and collaborative programs. The current program is investigating the challenges of improving performance, extending life, and miniaturizing designs. ${ }^{1}$ In 2001, an AIAA paper was presented on efforts by NASA and industry to advance the state-of-the-art in electrical components for pulsed plasma thrusters (PPT). ${ }^{2}$ Following the successful development of the Earth Observing-1 PPT, NASA Glenn Research Center (GRC) contracted with Unison Industries to develop advanced electrical components to meet future mission requirements. Unison teamed with Aerojet, then General Dynamics, and CU Aerospace. The effort included the breadboard level design and fabrication of a power processing unit (PPU), an energy storage unit (ESU), discharge initiation (DI) module and a spark plug. An evaluation of the components was presented in reference 3 . The system design philosophy is fully discussed in reference 2 . However, one design premise that could not be validated at the time was the concept of micropulsing.

Micropulsing controls the thrust by frequency and energy control as opposed to the more traditional energy control, ${ }^{4}$ where energy (E) is determined by the charge voltage and capacitance. By firing a PPT at lower energy but higher frequency (f) the same thrust (T) can be achieved as a higher energy PPT operating at a lower frequency. 
This allows the ESU to be utilized at the higher end of its rated storage capacity where it is more efficient. Thus minimizing the ESU mass by firing more frequently and reducing the ESU volume and mass. Mission analyses showed that most of the thruster operations occur at lower energies where the higher capacitance ESU is less efficient, and only occasionally required high thrust, such as missions requiring precise attitude control and formation flying. ${ }^{5,6,7}$

The ESU designed and fabricated for the original contract was a mica-foil capacitor. The ESU could be used at its rated energy storage capacity for most space low impulse bit $\left(\mathrm{I}_{\mathrm{bit}}\right)$ maneuvers but still have enough thrust for higher thrust maneuvers simply by increasing the operating frequency. For instance, instead of a PPT firing at a maximum of $50 \mathrm{~J}$ at $1 \mathrm{~Hz}$, a PPT operating at $5 \mathrm{~Hz}$ and $10 \mathrm{~J}$ should provide the same thrust. However, this premise could not be confirmed experimentally with the existing PPU hardware. Previous high energy performance data was acquired using oil-filled capacitors and the low energy micropulsing data was generated with mica foil capacitors. The differences in capacitor types make it difficult to compare the data. For one, the discharge characteristics (i.e. discharge current waveforms) are different for the two capacitor types and that has a strong impact on performance. Also the method of termination of the capacitor leads and the configuration of the PPTs used in previous tests are different and impact the results. For instance, the width of fuel bar, the gap between the electrodes and the length of the electrodes all impact performance. ${ }^{8}$

In order to determine if micropulsing achieves the same thrust as higher energy PPTs, and allows for minimizing requirements on the ESU, the following test was performed. An independent spark plug initiation unit, a high voltage power supply and a variety of mica foil capacitors would be used to conduct a series of tests on a single PPT to map performance levels over a comparable power range, of $50 \mathrm{~W}$ or less Higher capacitance ESUs were tested at a fixed frequency and varying energies. Lower capacitance ESUs were tested at a fixed energy but varying frequencies. For instance a $50 \mathrm{~J}$ ESU operating at $1 \mathrm{~Hz}$ can be compared to a $10 \mathrm{~J}$ ESU operating at $5 \mathrm{~Hz}$, or $50 \mathrm{~W}$. Testing at NASA GRC was conducted with breadboard PPT hardware. Test parameters were thrust, impulse bit, specific impulse $\left(\mathrm{I}_{\mathrm{sp}}\right)$ and efficiency $(\eta)$. Using the identical thruster in both high and low energy performance testing with the same type of ESU could verify that micropulsing is a valid option for PPU/PPT operations, and a way to reduce both ESU mass and volume.

\section{Test Description}

\section{A. Test Apparatus}

Testing occurred in a vacuum facility at NASA GRC. The vacuum facility is $1.5 \mathrm{~m}$ in diameter and is positioned horizontally along its long axis which is $4.5 \mathrm{~m}$ long. The tank generally operates in the $0.1 \mathrm{mPascal}$ range $\left(10^{-6}\right.$ Torr $)$. The vacuum is maintained by four oil diffusion pumps.

The thrust stand is a torsional type device that can used to measure both thrust and impulse bit. ${ }^{9}$ These performance parameters are calculated from the thrust stand deflection, spring stiffness and natural frequency. The thrust stand deflection is calibrated with in-situ weights that provide a known force to the thrust stand arm. The PPT can be operated in steady state mode to determine thrust or in individual pulse mode to determine impulse bit.

\section{B. Pulsed Plasma Thruster}

The PPT used was a laboratory model; it was designed neither for minimized mass or optimal performance. A photograph of the PPT is seen in figure 1. Figure 2 shows the thruster mounted on the thrust stand. The PPT has $1.27 \mathrm{~cm}$ wide electrodes and the length of the electrodes is only $1.91 \mathrm{~cm}$. The gap between the electrodes is $1.91 \mathrm{~cm}$. The spark plug is isolated from the cathode electrode and is housed inside the ceramic behind the cathode and fires through a hole in the cathode electrode just above the fuel bar surface. This provides for electrical isolation between the discharge initiation and ESU charging power supplies. The spark plug used was the $0.635 \mathrm{~cm}$ diameter semiconductor plug designed under the Unison contract.

For this test mica foil capacitors (ESUs) were used. Two different size ESUs where available; the ESU developed under the original contract, a $2.6 \mu \mathrm{F}$, and the other a $10 \mu \mathrm{F}$. To accomplish the highest energy testing two $10 \mu \mathrm{F}$ ESUs were connected in parallel for a $20 \mu \mathrm{F}$ configuration. An additional configuration where two $2.6 \mu \mathrm{F}$ ESUs were connected in parallel for a $5.3 \mu \mathrm{F}$ configuration was also tested. The respective mass and volumes of the four sets of ESUs are given in table 1. The mass ratio of the lower to higher capacitance is 1:3.7. The volume ratio is 
1:3.8. The mass of the smaller ESU is impacted by slightly more substantial connector leads which increase its mass. Without destructive analysis of the ESUs, an estimate of the mass of the smaller capacitor without the connectors results in a mass ratio closer to $1: 3.8$. Even though the $5.3 \mu \mathrm{F}$ and the $20 \mu \mathrm{F}$ configurations actually have two ESUs in parallel, those two configurations will be referred to as a single unit.

Energy densities are not included in the table because the numbers would be misleading. The maximum rated voltage of $2770 \mathrm{~V}$ the smaller ESU reflects de-rating to meet the requirements for a $10 \mathrm{~J}$ pulse over a long operational life, but in actual construction could be tested at much higher energies. ${ }^{2}$ The larger two $10 \mu \mathrm{F}$ were purchased "offthe-shelf" without a long life requirement and are rated for a maximum voltage of $2500 \mathrm{~V}$.

For all test configurations a primary high voltage power supply was used to select the discharge energy by controlling the voltage and current regulation on the power supply. Full ESU charge and discharge voltages and discharge frequency were verified with a digital oscilloscope.

\section{Discharge Initiation Circuit}

An independent discharge initiation circuit was built that allowed a small $0.20 \mu \mathrm{F}$ capacitor to be directly charged by a second high voltage power supply. This circuit allowed the spark plug to be discharged over a range of frequencies from 0.5 to $8 \mathrm{~Hz}$. The unit could be operated either in continuous mode where the PPT will discharge at a predetermined frequency or operated in a single discharge mode. By controlling the voltage and current regulation on the ESU power supply the discharge energy can be chosen, within the voltage and current limits of the power supplies and ESUs. Full ESU charge and discharge voltages and discharge frequency were verified with a digital oscilloscope.

\section{Test matrix}

To maintain consistency the thruster was tested with each ESU configuration generally over a power (P) range of 10 to $50 \mathrm{~W}$. The original PPU and ESU were designed for maximum operating power of $50 \mathrm{~W}$ on a single nozzle so it was chosen here as the maximum. The capacitance and voltage rating of each ESU determined the energy level and frequency required to test across this power range. Table 2 shows the frequency and energy level used for each of the four configurations to test across the power range. In some capacitance configurations, due to limitations of different system components, there was only one way to achieve a particular power level. For instance, for the $2.6 \mu \mathrm{F}$ ESU to achieve $50 \mathrm{~W}$, approached the voltage limits of the high voltage power supply and the charge characteristics of the ESU itself. That ESU could only be charged to a maximum of 10J and a maximum frequency $5 \mathrm{~Hz}$, so operation at $60 \mathrm{~W}$ was not feasible. However, there were several operating points that could have been tested at different energies or frequencies to achieve the same power. For each of the two configurations that have the two ESU in parallel it was simpler to charge to the same voltage as that ESU alone, and change the frequency by a factor of two to get the same power level. Also, the smaller capacitor could have been fired at decreased discharge voltages, but for the purpose of this study only a fixed discharge voltage was tested.

For each capacitor configuration, the thruster was operated over the power levels shown in table 2 . In the cases where the energy level remained constant over the range of power levels and only the frequency was changed, 30 individual shots were taken and averaged to determine impulse bit and multiple continuous mode runs of 2 to 3 minutes durations were taken to determine the nominal thrust. In the cases were the frequency remained constant across the power range and the energy level was changed, 30 individual shots were averaged to determine the impulse bit as were multiple continuous mode runs to determine thrust at each energy level.

To determine specific impulse and efficiency, a mass loss measurement was made at a single operating condition. Each ESU configuration was operated at 50W in continuous mode for over an hour, with a pre and post test mass measurement.

\section{Results and Discussion}

In figure 3, impulse bit is plotted as a function of energy for all capacitance values. The $2.6 \mu \mathrm{F}$ and $20 \mu \mathrm{F}$ cases were repeated on separate days as indicated by the one or two in parentheses after the capacitance value. This is impulse bit measured from the thrust stand parameters and not back calculated as a function of thrust and frequency. 
For the two $2.6 \mu \mathrm{F}$ cases and the single $5.3 \mu \mathrm{F}$ case, only one datum point was plotted since only one energy level was tested, $10 \mathrm{~J}$ or $20 \mathrm{~J}$, respectively. For the $10 \mu \mathrm{F}$ and $20 \mu \mathrm{F}$ ESUs, multiple impulse bit measurements were plotted, and results are shown in figure 3 . The curves are nearly coincidental with only a slight difference in impulse bit at $10 \mathrm{~J}$ for the $20 \mu \mathrm{F}$ cases and for the $10 \mu \mathrm{F}$ case up to the maximum tested energy of 25J. Since the plots are overlapping, uncertainties are presented in table 3 . The difference between the two $20 \mu \mathrm{F}$ datum at $10 \mathrm{~J}$ was larger than the uncertainty, but it was noted that after testing at this low energy there was some carbonization on the fuel bar surface which impacted the performance. Though the thrust data will be discussed shortly, a similar discrepancy between the $20 \mu \mathrm{F}$ cases was obtained at the thrust measurements at $10 \mathrm{~W}$, but there was good agreement between the calculated impulse bit from thrust and measured impulse bit from data taken with a single test day.

Figure 4 shows a plot of thrust versus power for all four capacitor configurations. The uncertainties for these plots are given in table 3 again because of the overlapping nature of the plots. For the two test days with the $2.6 \mu \mathrm{F}$ ESU, the data across the power range for 10 to $50 \mathrm{~W}$ was nearly identical. The same is true of the $20 \mu \mathrm{F}$ data. When compared to each other at the $50 \mathrm{~W}$ level both ESU configurations have nearly the same thrust. However, at the lower $10 \mathrm{~W}$ level the curves diverge with the $2.6 \mu \mathrm{F}$ ESU having higher thrust, on the order of about $50 \%$. This is because the lower value ESU was being operated closer to its maximum rated performance at $10 \mathrm{~J}$ as opposed the $20 \mu \mathrm{F}$ ESU which is only being operated at a fraction, $15 \%$, of its rated energy. The $5.3 \mu \mathrm{F}$ case nearly follows the curve as the $2.6 \mu \mathrm{F}$ case. However the $10 \mu \mathrm{F}$ case does appear to have significantly lower thrust than the other three cases. This might be initially unexpected given the near agreement for the impulse bit plots in figure 3 .

On further analysis of figure 3, as pointed out in a paper by $\operatorname{Guman}^{10}$ that for a given set of input conditions, capacitance and discharge voltage, the thrust-to-power (T/P) ratio should be independent of the pulse frequency.

$$
\mathrm{T}=\mathrm{f} \mathrm{I}_{\mathrm{bit}} \text { and } \mathrm{P}=\mathrm{f} \mathrm{E} \text { then } \mathrm{T} / \mathrm{P}=\mathrm{I}_{\mathrm{bit}} / \mathrm{E} \text {. }
$$

Also, that their experience was that the propellant geometry impacted the thrust-to-power ratio. In this particular study the same nozzle was used in all cases. For the capacitance configurations, $2.6 \mu \mathrm{F}$ and $5.3 \mu \mathrm{F}$ where energy was constant, the T/P ratio should be constant. For the $2.6 \mu \mathrm{F}$ cases the T/P was $9.2 \mu \mathrm{N} / \mathrm{W}+/-6 \%$ and for the $5.3 \mu \mathrm{F}$ was $9.0 \mu \mathrm{FN} / \mathrm{W}+/-2 \%$. Also, as the thrust is varied the specific impulse and thruster efficiency remain constant. However, when capacitance and discharge voltage change across the power range as with the $10 \mu \mathrm{F}$ and $20 \mu \mathrm{F}$ cases; thrust-to-power is no longer constant or independent of the frequency. The thrust-to-power for the $10 \mu \mathrm{F}$ cases varies from $6.6 \mu \mathrm{N} / \mathrm{W}$ at $10 \mathrm{~W}$ to $9.4 \mu \mathrm{N} / \mathrm{W}$ at $50 \mathrm{~W}$. While the thrust to power for the $20 \mu \mathrm{F}$ varies from $5.7 \mu \mathrm{N} / \mathrm{W}$ at $10 \mathrm{~W}$ to $9.5 \mu \mathrm{N} / \mathrm{W}$ at $50 \mathrm{~W}$. Hence even though there is good agreement between the plots of the impulse bit versus energy, the selection of frequency and energy does impact the thrust.

The method for selecting frequency and energy level for different power levels does impact the overall thrust. A way to illustrate this is to examine the $10 \mu \mathrm{F}$ case. At $30 \mathrm{~W}$, the ESU was charged to $15 \mathrm{~J}$. The resultant impulse bit measurement fell on the same curve as the $20 \mu \mathrm{F}$ ESU. However, the $10 \mu \mathrm{F}$ ESU was operated at $2 \mathrm{~Hz}$ to achieve $30 \mathrm{~W}$ power level which resulted in thrust that was almost $18 \%$ less than the other three cases. However, the $10 \mu \mathrm{F}$ ESU was also fired at $30 \mathrm{~J}$ and $1 \mathrm{~Hz}(30 \mathrm{~W})$, and the thrust was measured at $251 \mu \mathrm{N}$ which is within the uncertainty of the other 3 configurations. Hence, when the $10 \mu \mathrm{F}$ ESU was used at lower energies it became less efficient. The difference is not observed between the $2.6 \mu \mathrm{F}$ and $5.3 \mu \mathrm{F}$ configuration because in that case both ESU were used at their maximum energy. Studies ${ }^{11,12}$ have shown that as thrust-to-power decreases for lower energy discharges so will the specific impulse and thruster efficiency.

Table 4 shows the specific impulse and efficiency calculated from the thrust measurements of each of the four configurations at $50 \mathrm{~W}$ operation. While the specific impulse and efficiency are expect to remain constant across the lower power ranges for the two lower capacitance configurations, for the two higher capacitance configurations the specific impulse will drop. The specific impulse ranged from approximately $2000 \mathrm{sec}$ for the $50 \mathrm{~J} 20 \mu \mathrm{F}$ case to approximately $500 \mathrm{sec}$ for the $10 \mathrm{~J} 2.6 \mu \mathrm{F}$ case. The specific impulse for the $5.3 \mu \mathrm{F}$ and $10 \mu \mathrm{F}$ cases were approximately $890 \mathrm{sec}$ and $1180 \mathrm{sec}$, respectively. Efficiencies range from $2.4 \%$ for the $2.6 \mu \mathrm{F}$ cases to $9.9 \%$ and $9.2 \%$ for the $20 \mu \mathrm{F}$ cases. For the four ESU configurations at $50 \mathrm{~W}$ operation, while three have approximately the same thrust, the efficiency and specific impulse increased by almost a factor of four for the highest value of capacitance. However as shown earlier in table 1, the mass and volume of the capacitors increase to almost a factor of four from lowest to highest capacitance.

These can be related back to the peak currents which are given in figure 5. The figure shows a plot of the current discharge profile for each capacitor configuration at its highest energy discharge. The exception being a current profile for the $20 \mu \mathrm{F}$ case at $10 \mathrm{~J}$ has been added. This was added to allow for the comparison to the 
$10 \mathrm{~J}-2.6 \mu \mathrm{F}$ case. Peak current was $16.4 \mathrm{kA}$ for the $20 \mu \mathrm{F}$ configuration at $50 \mathrm{~J}$. For the $2.6 \mu \mathrm{F}$ and the $20 \mu \mathrm{F}$ at $10 \mathrm{~J}$ cases the peak currents were $8.7 \mathrm{kA}$ and $6.9 \mathrm{kA}$, respectively, leading to the expectation of a higher impulse bit for the $2.6 \mu \mathrm{F}$ case over the $20 \mu \mathrm{F}$ capacitor at the same energy which was the case. Regardless, the trade off would be for high power operations between mass and volume or specific impulse and efficiency. But for a primarily low energy mission a constant energy discharge has the potential advantage of both higher thrust-to-power and lower mass while satisfying higher end thrust requirements.

\section{Conclusions}

Micropulsing is a method of PPT operation where both the discharge frequency and discharge energy could be varied to take advantage of a smaller capacitor size over a more traditional discharge energy control scheme. While only the frequency control aspect of the smaller capacitor was investigated, varying the energy should have mirrored effects of the larger capacitor with decreasing T/P ratios, specific impulse and efficiency. However the operational range could increase by allowing operations at lower power than tested in this study. For the capacitor configurations tested over a 10 to $50 \mathrm{~W}$ power range, micropulsing did provide a method for achieving the equivalent maximum nominal thrust at the high end of the power range while providing considerable capacitor mass and volume savings, but at the expense of specific impulse and efficiency. However, because micropulsing also provides a consistent thrust-to-power over an operating range for missions where most operations would occur in the lower end of an operational range, it would be most effective in providing both better impulse bit and thrust. Also at the lower operating range it could provide an improvement in specific impulse and efficiency over the larger capacitor at the same power range.

\section{References}

${ }^{1}$ Pencil, E.J., Kamhawi, H., and Arrington, L.A., “Overview of NASA's Pulsed Plasma Thruster Development Program,” AIAA 2004-3455, July 2004.

${ }^{2}$ Benson, S.W. and Frus, J.R., “Advanced Pulsed Plasma Thruster Electrical Components,” AIAA 2001-3894, July 2001.

${ }^{3}$ Pencil, E.J., Arrington, L.A., and Carter, T.J., "Evaluation of Pulsed Plasma Thruster Electrical Component," AIAA 20013899 , July 2001.

${ }^{4}$ Benson, S.W., Arrington, L.A., Hoskins, W.A., and Meckel, N.J., "Development of a PPT for the EO-1 Spacecraft," AIAA 992276, June 1999.

${ }^{5}$ Blandino, J.J., Cassady, R.J., and Peterson, T.T. "Pulsed Plasma Thrusters for the New Millennium Interferometer (DS-3) Mission," IEPC-97-192, March 1997.

${ }^{6}$ Deininger, W.D., et al., "Description of the StarLight Mission and Spacecraft Concept,” IEEE 2001-277, March 2001.

${ }^{7}$ Deininger, W.D., et al., "Pulsed Plasma Thruster System for Precision Formation Flying," "International Symposium on Formation Flying Missions and Technologies," Toulouse France, 29-31 October 2003.

${ }^{8}$ Arrington, L.A., Haag, T.W., Pencil, E.J., and Meckel, N.J., "A Performance Comparison of Pulsed Plasma Thruster Electrode Configurations," IEPC 97-127, August 1997.

${ }^{9}$ Haag, T.W., “PPT Thrust Stand,” AIAA Paper 95-2917, July 1995.

${ }^{10}$ Guman, W.J., “Designing Solid Propellant Pulsed Plasma Thruster,” AIAA Paper A75-410, March 1975.

${ }^{11}$ Guman, W.J., Peko, P.E., “Solid Propellant Pulsed Plasma Micro-Thrustor Studies,” AIAA Paper A68-85, January 1968.

${ }^{12}$ Pencil, E.J., and Kamhawi, H., “Alternate Propellant Evaluation for 100-joule-class Pulsed Plasma Thrusters,” AIAA 20035171, July 2003. 
TABLE 1.-ESU PROPERTIES

\begin{tabular}{||l|c|c|c|c||}
\hline & $2.66 \mu \mathrm{F}$ & $5.34 \mu \mathrm{F}$ & $10.09 \mu \mathrm{F}$ & $20.18 \mu \mathrm{F}$ \\
\hline Configuration & Single, $2.6 \mu \mathrm{F}$ & Parallel, $2.66 \mu \mathrm{F}$ & Single, $10.09 \mu \mathrm{F}$ & Parallel, $10.09 \mu \mathrm{F}$ \\
\hline Mass, $\mathrm{kg}$ & 0.652 & 1.30 & 1.19 & 2.39 \\
\hline Volume, $\mathrm{cm}^{3}$ & 276 & 552 & 526 & 1050 \\
\hline Normalized Mass & 1 & 2 & 1.8 & 3.7 \\
\hline Normalized Volume & 1 & 2 & 1.9 & 3.8 \\
\hline
\end{tabular}

TABLE 2.-EST MATRIX FOR VARIOUS CAPACITOR CONFIGURATIONS

\begin{tabular}{|c|c|c|c|c||}
\hline \hline Power, W & $2.66 \mu \mathrm{f}$ & $5.34 \mu \mathrm{f}$ & $10.09 \mu \mathrm{f}$ & $20.18 \mu \mathrm{f}$ \\
\hline 10 & $10 \mathrm{~J}, 1 \mathrm{~Hz}$ & -- & -- & $10 \mathrm{~J}, 1 \mathrm{~Hz}$ \\
\hline 20 & $10 \mathrm{~J}, 2 \mathrm{~Hz}$ & $20 \mathrm{~J}, 1 \mathrm{~Hz}$ & $10 \mathrm{~J}, 2 \mathrm{~Hz}$ & $20 \mathrm{~J}, 1 \mathrm{~Hz}$ \\
\hline 30 & $10 \mathrm{~J}, 3 \mathrm{~Hz}$ & $20 \mathrm{~J}, 1.5 \mathrm{~Hz}$ & $15 \mathrm{~J}, 2 \mathrm{~Hz}$ & $30 \mathrm{~J}, 1 \mathrm{~Hz}$ \\
\hline 40 & $10 \mathrm{~J}, 4 \mathrm{~Hz}$ & $20 \mathrm{~J}, 2 \mathrm{~Hz}$ & $20 \mathrm{~J}, 2 \mathrm{~Hz}$ & $40 \mathrm{~J}, 1 \mathrm{~Hz}$ \\
\hline 50 & $10 \mathrm{~J}, 5 \mathrm{~Hz}$ & $20 \mathrm{~J}, 2.5 \mathrm{~Hz}$ & $25 \mathrm{~J}, 2 \mathrm{~Hz}$ & $50 \mathrm{~J}, 1 \mathrm{~Hz}$ \\
\hline
\end{tabular}

*Actual point was taken at $1.33 \mathrm{~Hz}$ discovered post test (power $=27 \mathrm{~W})$.

-- Indicates no data was taken at this point.

TABLE 3.-UNCERTAINTY PERCENTAGES

\begin{tabular}{|c|c|c|c|c|c|c|c|}
\hline & & \multicolumn{6}{|c|}{ Capacitance, $\mu \mathrm{F}$} \\
\hline & Power/Energy & $2.66(1)$ & $2.66(2)$ & 5.34 & 10.09 & $20.18(1)$ & $20.18(2)$ \\
\hline \multirow[t]{5}{*}{ Thrust } & $10 \mathrm{~W}$ & 3.4 & 3.4 & -- & -- & 2.2 & 2.7 \\
\hline & $20 W$ & 2.3 & 1.8 & 3.2 & 2.9 & 1.8 & 0.9 \\
\hline & $30 \mathrm{~W}$ & 2.0 & 1.3 & 2.5 & 2.0 & 1.2 & 1.2 \\
\hline & $40 \mathrm{~W}$ & 1.8 & 1.1 & 1.6 & 3.6 & 1.6 & 1.0 \\
\hline & $50 \mathrm{~W}$ & 2.1 & 1.0 & 1.4 & 2.1 & 1.3 & 0.7 \\
\hline \multirow{5}{*}{$\begin{array}{c}\text { Impulse } \\
\text { Bit }\end{array}$} & $10 \mathrm{~J}$ & 1.8 & 1.8 & -- & 3.2 & 3.1 & 3.8 \\
\hline & $20 \mathrm{~J}$ & -- & -- & 1.1 & $2.2(15 \mathrm{~J})$ & 1.3 & 1.4 \\
\hline & $30 \mathrm{~J}$ & -- & -- & -- & $1.9(20 \mathrm{~J})$ & 0.9 & 0.9 \\
\hline & $40 \mathrm{~J}$ & -- & -- & -- & $1.7(25 \mathrm{~J})$ & 0.7 & 0.7 \\
\hline & $50 \mathrm{~J}$ & -- & -- & -- & -- & 0.5 & 0.6 \\
\hline $\begin{array}{l}\text { Specific } \\
\text { Impulse }\end{array}$ & $50 \mathrm{~W}$ & 0.9 & 1.8 & 2.0 & 0.9 & 2.7 & 3.2 \\
\hline Efficiency & $50 \mathrm{~W}$ & 1.2 & 2.6 & 2.4 & 1.3 & 3.6 & 4.5 \\
\hline
\end{tabular}

-- Indicates no data was taken at this point.

TABLE 4.-SPECIFIC IMPULSE AND EFFICIENCY CALCULATED FROM DATA TAKEN AT 50 WATTS CONTINUOUS OPERATION

\begin{tabular}{||c|c|c|c|c|c|c||}
\hline Capacitance, $\mu \mathrm{f}$ & $2.66(1)$ & $2.66(2)$ & 5.34 & 10.09 & $20.18(1)$ & $20.18(2)$ \\
\hline Energy, J & 10 & 10 & 20 & 25 & 50 & 50 \\
\hline $\begin{array}{c}\text { Specific Impulse, } \\
\text { sec }\end{array}$ & 500 & 508 & 891 & 1170 & 2080 & 1990 \\
\hline Efficiency, (\%) & 2.4 & 2.4 & 4.1 & 4.7 & 9.9 & 9.2 \\
\hline
\end{tabular}




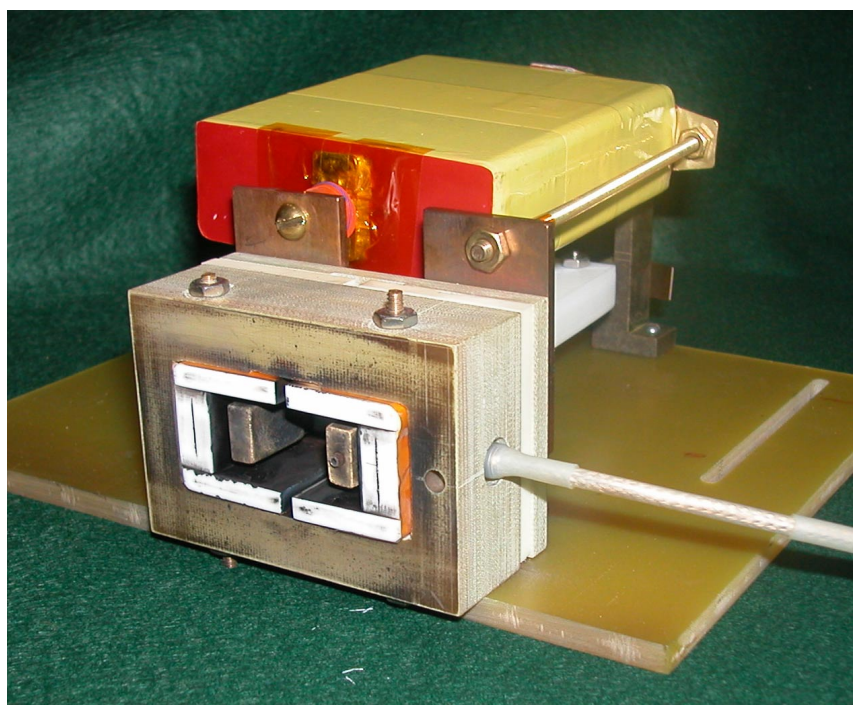

Figure 1.—Laboratory PPT with mica foil capacitor.

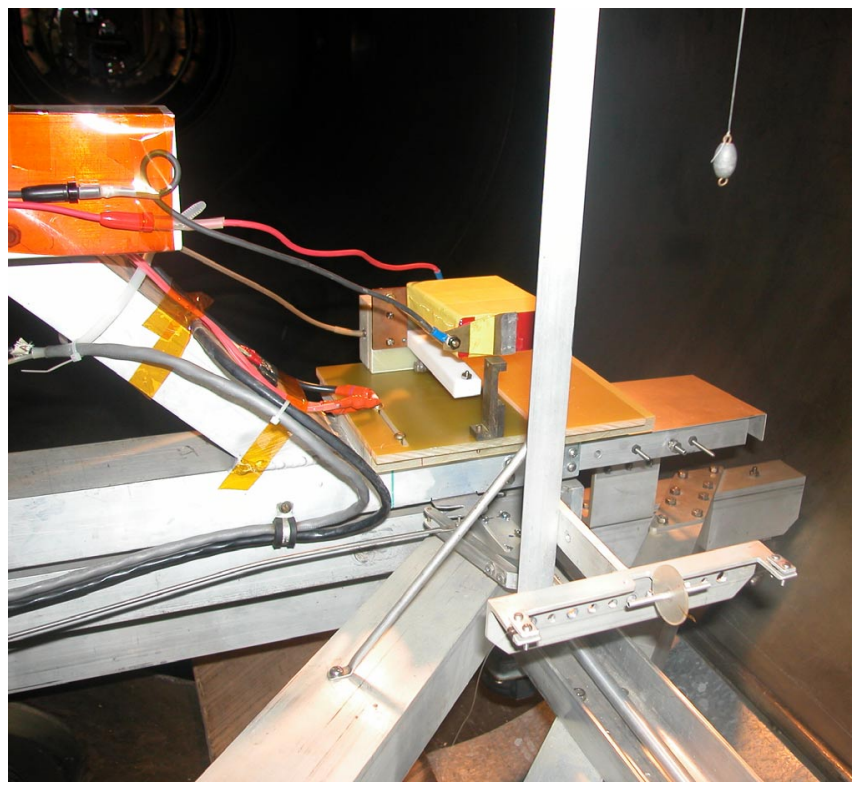

Figure 2.-PPT installed on thrust stand. 


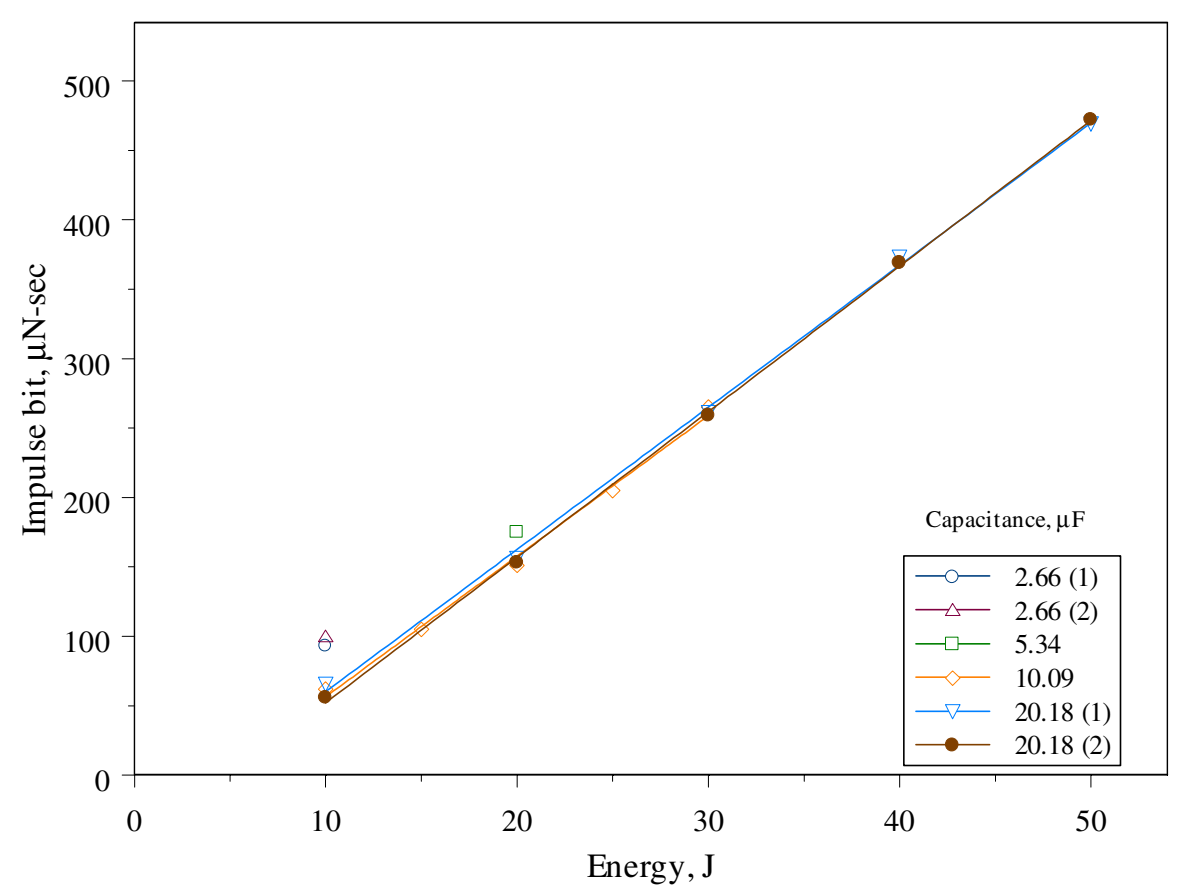

Figure 3.-Impulse bit versus energy for different capacitances.

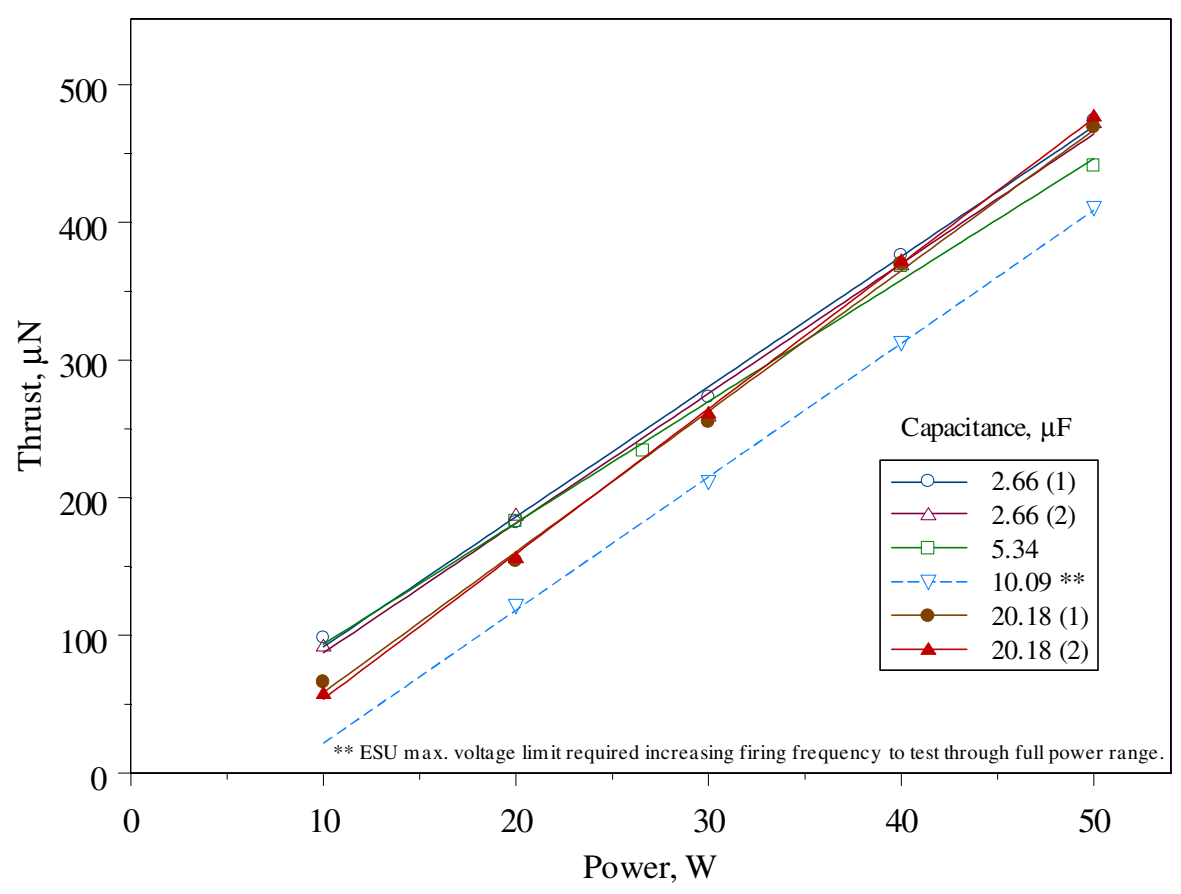

Figure 4.-Thrust versus power for different capacitances. 


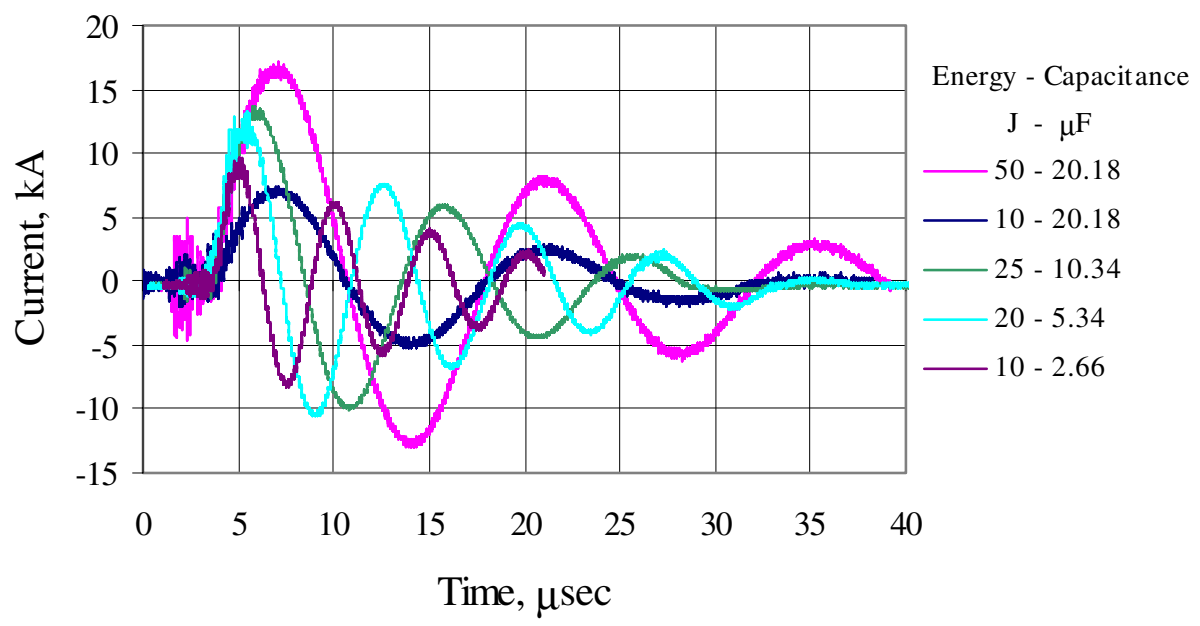

Figure 5.-Current waveforms versus time at various energies and capacitances. 
Public reporting burden for this collection of information is estimated to average 1 hour per response, including the time for reviewing instructions, searching existing data sources, gathering and maintaining the data needed, and completing and reviewing the collection of information. Send comments regarding this burden estimate or any other aspect of this collection of information, including suggestions for reducing this burden, to Washington Headquarters Services, Directorate for Information Operations and Reports, 1215 Jefferson Davis Highway, Suite 1204, Arlington, VA 22202-4302, and to the Office of Management and Budget, Paperwork Reduction Project (0704-0188), Washington, DC 20503.

\begin{tabular}{|l|l|l}
\hline 1. AGENCY USE ONLY (Leave blank) & $\begin{array}{c}\text { 2. REPORT DATE } \\
\text { August } 2004\end{array}$ & $\begin{array}{c}\text { 3. REPORT TYPE AND DATES COVERED } \\
\text { Final Contractor Report }\end{array}$
\end{tabular}

4. TITLE AND SUBTITLE 5. FUNDING NUMBERS

Evaluation of Pulsed Plasma Thruster Micropulsing

6. AUTHOR(S)

Lynn Arrington

WBS-22-319-20-D2

NAS3-00145

7. PERFORMING ORGANIZATION NAME(S) AND ADDRESS(ES)

8. PERFORMING ORGANIZATION REPORT NUMBER

QSS Group, Inc.

21000 Brookpark Road

E-14717

Cleveland, Ohio 44135

9. SPONSORING/MONITORING AGENCY NAME(S) AND ADDRESS(ES)

National Aeronautics and Space Administration

Washington, DC 20546-0001

10. SPONSORING/MONITORING AGENCY REPORT NUMBER

NASA CR-2004-213209

AIAA-2004-3458

\section{SUPPLEMENTARY NOTES}

Prepared for the 40th Joint Propulsion Conference and Exhibit cosponsored by AIAA, ASME, SAE, and ASEE, Fort Lauderdale, Florida, July 11-14, 2004. Project Manager, Eric Pencil, Power and On-Board Propulsion Technology Division, NASA Glenn Research Center, organization code 5430, 216-977-7463.

Unclassified - Unlimited

Subject Category: 20

Distribution: Nonstandard

Available electronically at http://gltrs.grc.nasa.gov

This publication is available from the NASA Center for AeroSpace Information, 301-621-0390.

13. ABSTRACT (Maximum 200 words)

This paper evaluates the concept of pulsed plasma thruster (PPT) micropulsing. Micropulsing was a premise behind a power processing unit (PPU) and an energy storage unit (ESU) design that for certain mission profiles, it was advantageous to operate a PPT at lower energy but higher frequency rather than at a higher energy but lower frequency. This premise allows for reductions in the ESU volume and mass without paying a penalty in thrust. To complete the evaluation, an independent spark plug initiation unit, a high voltage power supply and a variety of mica foil capacitors at 2.6, 5, 10, and $20 \mu \mathrm{F}$ were used to conduct a series of tests on a single PPT to map performance levels of thrust, impulse bit, efficiency and specific impulse over a comparable power range. Testing at NASA Glenn Research Center was conducted with breadboard PPT hardware. The test results showed that operating in the lower energy ESU micropulsing mode produced similar thrust levels to a higher energy ESU operating at high power level. Further testing however showed a reduction in specific impulse and efficiency when the smaller capacitances were used at the highest power levels. This would require more fuel mass for a mission that was predominately high power, potentially negating the ESU mass savings. Therefore, micropulsing is advantageous where most of a mission profile occurs at low power, but retains the ability to conduct high thrust maneuvers when necessary.

14. SUBJECT TERMS

Micropulsing; Pulsed plasma thruster; Performance; Thrust; Impulse bit 15

\begin{tabular}{|c|c|c|}
\hline $\begin{array}{c}\text { 17. SECURITY CLASSIFICATION } \\
\text { OF REPORT } \\
\text { Unclassified }\end{array}$ & $\begin{array}{c}\text { 18. SECURITY CLASSIFICATION } \\
\text { OF THIS PAGE } \\
\text { Unclassified }\end{array}$ & $\begin{array}{c}\text { 19. SECURITY CLASSIFICATION } \\
\text { OF ABSTRACT } \\
\text { Unclassified }\end{array}$ \\
\hline
\end{tabular}

NSN 7540-01-280-5500

Standard Form 298 (Rev. 2-89) 

